\title{
Epidemiological study of road traffic accident cases visiting emergency department of Osmania general hospital, Hyderabad, Telangana, India
}

\author{
B. Baburao ${ }^{1}$, G. Sudha Rani ${ }^{2} *$
}

\footnotetext{
${ }^{1}$ Associate professor and HOD Osmania medical college, Osmania Medical College, Hyderabad, Telangana, India

${ }^{2}$ Assistant professor, Kakatiya Medical College, Warangal, Telangana, India
}

Received: 28 January 2016

Accepted: 03 March 2016

\section{*Correspondence:}

Dr. G. Sudha Rani

Email: drsudhagurram@gmail.com

Copyright: (c) the author(s), publisher and licensee Medip Academy. This is an open-access article distributed under the terms of the Creative Commons Attribution Non-Commercial License, which permits unrestricted non-commercial use, distribution, and reproduction in any medium, provided the original work is properly cited.

\section{ABSTRACT}

Background: World Health Organization defines road traffic injury (RTI) as a fatal or nonfatal injury incurred as a result of a collision on a public road involving at least one moving vehicle and pedestrians. Accident has been defined as an unexpected, unplanned occurrence, which involves injury. Road accident is treated as a major epidemic of noncommunicable disease in the present century. The objective of the study was to know the various epidemiological factors related to road traffic accident cases.

Methods: This study was conducted at Osmania General Hospital, Hyderabad, Telangana, South India from $1^{\text {st }}$ January to $31^{\text {st }}$ December 2013 . The study group-consisted of all the RTA victims reporting to casualty in the above one year period.

Results: A total of 1158 RTA cases reported at Osmania General Hospital during study period. Out of 1158 RTA cases $1026(88.6 \%)$ of the victims were males \& rest $132(11.4 \%)$ were female. The highest number of victims $601(51.8 \%)$ were from 16 - 30 years of age group. Followed by $291(25.1 \%)$ in the age group $31-45$ years. Motorized two-wheeler occupants were highest in number i.e. $898(77.5 \%)$ followed by occupants of four wheelers 147 (12.6\%). Pedestrians involved were 82 (7\%). Being knocked down was the common mode of RTA, involving 502 victims (43.3\%), followed by falling off vehicles which claimed 241(20.8\%) victims. Other modes were collision between two vehicles (18.8\%), run over (5.9\%) and due to overturning (7.0\%). Interestingly $130(11.2 \%)$ victims were injured due to the vehicle hitting a stationary object (parked vehicle). In the present study it was observed that time factor (to reach hospital) is very crucial for increase the chance of survival among RTA victims, death rate significantly low $7 \%$ among those who reached within 30minutes in comparison to those who took more time to reach the hospital. Majority (89\%) did not use any safety measures. Only 3\% used car seat belt and $8 \%$ wear helmet. The effect of alcohol was evident with $62 \%$ were consumed alcohol.

Conclusion: It was found that greater portion of the RTA occurred due to collusion between two vehicles followed by defective road. A significant number of accidents took place during bad weather. More than half of the accidents occurred due to wrong side driving.

Key words: Accident, Vehicles, Injury, Protective gears, Alcohol

\section{INTRODUCTION}

World Health Organization defines road traffic injury (RTI) as a fatal or nonfatal injury incurred as a result of a collision on a public road involving at least one moving vehicle and pedestrians. Accident has been defined as an unexpected, unplanned occurrence, which involves injury. Road accident is treated as a major epidemic of non-communicable disease in the present century. They are no longer considered accidental rather than they are part of the price we pay for technological progress. ${ }^{1}$ RTAs are the fourth in order among the leading causes of 
total death. Accidents are responsible for approximately $10 \%$ of all global deaths and $16 \%$ of global disabilities. Common victims of death caused by accidents are young age groups (10-24 years). ${ }^{2}$ Furthermore, according to the World Health Organization, the number of road traffic deaths is expected to increase by $80 \%$ up to 2020 [2]. Globally, road traffic injuries are ranked ninth among the leading causes of disability adjusted life years lost (DALY), and their ranking is projected to rise to third by $2020 .^{3,4}$

Accidents have their own natural history and follow the same epidemiological pattern as any other disease -that is, the agent, the host and the environment interacting together to produce injury or damage. They occur more frequently in certain age-groups, at certain times of day and week and at certain localities. Some people are more prone to accidents than others and susceptibility is increased by the effect of alcohol and other drugs as well as physiological state such as fatigue. Lastly, a majority of accidents are preventable. Road traffic accident are essentially caused by 1) Rapid increase in personalized modes of transport (agent) 2) A lack of road discipline (host) and 3) Improper roadway features (Environment). ${ }^{5}$

The economic cost of road crashes and injuries is enormous. Estimates suggest that they cost low and middle-income countries between $1 \%$ and $1.5 \%$ of their gross national product (GNP) and high-income countries $2 \%$ of GNP. ${ }^{6}$ Economic cost are just the tip of iceberg for everyone killed, injured or disabled by a road traffic crash there are countless others deeper in to poverty by the expenses of prolonged medical care, loss of a family bread winner or the added burden of caring for the disabled. $^{7}$ A high prevalence of old vehicles that often carry many more people than they are designed to carry, lack of safety belt and helmet use, poor road design and maintenance and the traffic mix on road are other factors that contribute to the high rate of crashes in India. ${ }^{8} \mathrm{~A}$ huge number of researches have been conducted to analyse road crashes. This paper aims to critically analyse the epidemiology of road traffic accident.

The objective of the study was to know the various epidemiological factors related to road traffic accident cases.

\section{METHODS}

This study was conducted at Osmania General Hospital, Hyderabad, Telangana, South India from $1^{\text {st }}$ January to $31^{\text {st }}$ December 2013. The study group-consisted of all the RTA victims reporting to casualty in the above one year period. For the purpose of the study, a Road Traffic Accident (RTA) was defined as accident, which took place on the road between two or more objects, one of which must be any kind of a moving vehicle. Any injury on the road without involvement of a vehicle (e.g. a person slipping and falling on the road and sustaining injury) or injury involving a stationary vehicle (e.g. persons getting injured while washing or loading a vehicle) or death due to RTA were excluded from the study. Associated factors like safety measures taken, influence of alcohol, and time of the accident were considered. The victims of the accidents were interviewed to obtain the information about the circumstances leading to accident. A pre-tested proforma specially designed for this purpose was used for interviewing the accident victims, either in the casualty or in the wards of Osmania General Hospital. Where the condition of the victims did not warrant the interview, the relatives or attendants were interviewed. The information collected consisted of personal identification data, time, date, day and type of vehicles involved in RTA, protective gear worn and category of road users. The medico-legal records and case sheets were referred for collecting additional information and where necessary for cross-checking. Data analysis done by using Epinfo 3.5.1, MS excel and statistical test done are chi-square, percent.

\section{RESULTS}

A total of 1158 RTA cases reported at Osmania general hospital during study period. Out of 1158 RTA cases $1026(88.6 \%)$ of the victims were males \& rest 132 $(11.4 \%)$ were female. The highest number of victims 601 $(51.8 \%)$ were from $16-30$ years of age group. Followed by $291(25.1 \%)$ in the age group 31-45 years. Motorized two-wheeler occupants were highest in number i.e. 898 (77.5\%) followed by occupants of four wheelers 147 $(12.6 \%)$. Pedestrians involved were 82 (7\%) being knocked down was the common mode of RTA, involving 502 victims (43.3\%), followed by falling off vehicles which claimed $241(20.8 \%)$ victims. Other modes were collision between two vehicles $(18.8 \%)$, run over $(5.9 \%)$ and due to overturning (7.0\%). Interestingly $130(11.2 \%)$ victims were injured due to the vehicle hitting a stationary object (parked vehicle).

Table 1: Distribution of RTA cases according to type of injury.

\begin{tabular}{|lll|}
\hline Type of injury & Number & Percentage \\
\hline Head injury & 566 & 48.9 \\
\hline Fracture of lower limb & 310 & 26.7 \\
\hline Fracture of upper limb & 128 & 11.0 \\
\hline Chest injury & 86 & 7.5 \\
\hline Others & 68 & 5.9 \\
\hline
\end{tabular}

In the present study it was observed that time factor (to reach hospital) is very crucial for increase the chance of survival among RTA victims, death rate significantly low $7 \%$ among those who reached within 30minutes in comparison to those who took more time to reach the hospital. Majority (89\%) did not use any safety measures. Only $3 \%$ used car seat belt and $8 \%$ wear helmet. The effect of alcohol was evident with $62 \%$ were consumed alcohol. 
Table 2: Time of occurrence.

\begin{tabular}{|lll|}
\hline Time & Number & Percentage \\
\hline 8 AM-6 PM & 182 & 15.7 \\
\hline 6 PM-12 AM & 849 & 73.4 \\
\hline 12 AM-8 AM & 127 & 10.9 \\
\hline
\end{tabular}

\section{DISCUSSION}

The results of the present study revealed that 1026 $(88.6 \%)$ of the victims were males \& the rest $132(11.4 \%)$ were females. According to a study done by Nilamber $\mathrm{J}$ et al in JIPMER, 603(83\%) were also males \& $123(17 \%)$ were females. ${ }^{9}$ The highest no of victims $601(51.8 \%)$ were from 16-30 year of age group, in a hospital based study by Ganveer GB majority of the victims were in the age group 18-37years. ${ }^{10}$ This show that the people of the most active \& productive age group are involved in RTA. In the present study the peak time for accidents was between $6.00 \mathrm{pm}$ to $12.00 \mathrm{pm} 783(62 \%)$ between 8.00 am to $6.00 \mathrm{pm}$ also a high number of RTA were observed $330(26 \%)$. Peak times for accidents were also reported in south india. ${ }^{9}$ Effect of alcohol was evident, its much higher when compared to the study conducted by Sood S. ${ }^{11}$ Our study also showed that those who drank alcohol were more likely to have road traffic injury as compared to those Who do not use alcohol $(P<0.001$; AOR: 2.918 (1.614-5.276)).The role of alcohol in impairing driving ability is well documented. Also the impairment increases as the blood alcohol level rises. In addition, the risk of accidents is higher in youngsters and elderly people for the same blood alcohol levels. ${ }^{12}$ In this present study $89 \%$ did not used any protective gears. Passenger cars tend to be older and do not have air bags, collapsible steering columns or other crash protective features. In addition, vehicles are not as well maintained. Poor road and landuse planning often leads to a deadly mix of high-speed through traffic accentuating the risk of accidents. Results show important observation in present study the relationship between time taken to reach hospital \& mortality among RTA cases, more death occurs victims reach the hospital after 1 hour similar finding was observe by Mishra B at el. ${ }^{13}$ This observation shows that time factor is very crucial for better outcome of RTA cases. Need for taking urgent steps for establishing ambulance services and provision of pre-hospital care \& trauma services is very essential.

\section{CONCLUSION}

This study was conducted with a view to explore the risk factors related to road traffic accident. Most of the victims were passengers, pedestrians and drivers. It was found that greater portion of the RTA occurred due to collusion between two vehicles followed by defective road. A significant number of accidents took place during bad weather. More than half of the accidents occurred due to wrong side driving. On the basis of the findings, it may be recommended that a greater part of RTA can be prevented by imposing specific protective measures and taking personal precautions and Traffic rules.

\section{Funding: No funding sources \\ Conflict of interest: None declared \\ Ethical approval: The study was approved by the Institutional Ethics Committee}

\section{REFERENCES}

1. World Health Organization (WHO) 1957. Technical Report Serial No. 118.

2. Director General, WHO. World Health Report 2004.

3. World Health Organization, The Injury Chart book: A Graphical Overview of the Global Burden of Injuries, World Health Organization, Geneva, Switzerland, 2002.

4. Lyons RA, Ward H, Brunt H. Using multiple datasets to understand trends in serious road traffic casualties. Accident Analysis and Prevention. 2008;40(4):1406-10.

5. Kaul V, Dattatreya D. A brief medico - socio demographic profile of non-fetal road traffic accident cases admitted to Karnataka institute of medical sciences. Scho Res J. 2011;1:32-6.

6. Transport research laboratory Report by Jacobs G, Aeron-Thomas A, Estimating global road fatalities crow Thorne. 2000;no.445.

7. Nantulya VM, Reich MR. Eguity dimensions of road traffic injuries in low and middle - income countries. Injury control \& safety promotion. 2003;10:13-20.

8. Mondal P, Kumar A, Bhangale UD. A silent tsunami on Indian Road: A comprehensive Analysis of epidemiological aspect ofroad traffic accidents. BJM. 2011;1(1):14-23.

9. Nilamber J, Goutam R, Jagdish S. Epidemiological study of Road traffic cases: A study from south India. IJCM. 2004;xxi(1):20-4.

10. Ganveer GB, Tiwari RR. Injury pattern among nonfatal Road traffic accident cases: a cross sectional study in central. Indian J Med Sci. 2005;59(1):9-12.

11. Sood S. Survey of seven factors Influencing Injury among riders involved in motorized two wheeler accidents in India: A prospective study of 302 cases. Journal of Trauma 1988;28(4):530-4.

12. WHO. Road traffic accidents in developing countries. Technical report series No. 73. World Health Organization, Geneva 1984.

13. Mishra B. Epidemiological study of road traffic accident cases from western Nepal. IJCM. 2010;35:115-21.

Cite this article as: Baburao $\mathrm{B}$, Sudha Rani G. Epidemiological study of road traffic accident cases visiting emergency department of Osmania general hospital, Hyderabad, Telangana, India. Int $\mathbf{J}$ Community Med Public Health 2016;3:875-7. 